\title{
Qualidade fenólica em cultivares de uva submetida a poda verde e regulador hormonal
}

\author{
Phenolic quality in grape cultivars submitted to green pruning and hormonal regulator \\ Calidad fenólica en cultivares de uva sometidos a poda en verde y regulador hormonal
}

Recebido: 24/03/2021 | Revisado: 02/04/2021 | Aceito: 05/04/2021 | Publicado: 15/04/2021

\author{
Isabela Leticia Pessenti \\ ORCID: https://orcid.org/0000-0002-5176-3134 \\ Universidade Estadual de Ponta Grossa, Brasil \\ E-mail: isabelaleticiapessenti@gmail.com \\ Ricardo Antonio Ayub \\ ORCID: https://orcid.org/0000-0003-3240-8417 \\ Universidade Estadual de Ponta Grossa, Brasil \\ E-mail: rayub@uepg.br \\ Heverton Fernando Melo \\ ORCID: https://orcid.org/0000-0002-4869-0341 \\ Universidade Estadual de Ponta Grossa, Brasil \\ E-mail: hevertonfernando@gmail.com \\ Warlyton Silva Martins \\ ORCID: https://orcid.org/0000-0002-7284-3395 \\ Universidade Estadual de Ponta Grossa, Brasil \\ E-mail: warlytonsilva@gmail.com \\ Lucia Helena Wiecheteck \\ ORCID: https://orcid.org/0000-0002-6345-0135 \\ Universidade Estadual de Ponta Grossa, Brasil \\ E-mail: luwick@gmail.com \\ Renato Vasconcelos Botelho \\ ORCID: https://orcid.org/0000-0001-9580-2572 \\ Universidade Centro Oeste do Paraná, Brasil \\ E-mail: rbotelho@unicentro.br
}

\begin{abstract}
Resumo
A cor e estabilidade das antocianinas em frutas são amplamente influenciadas pela temperatura, luz e pH. Neste sentido, o presente trabalho objetivou avaliar o manejo da desfolha e da aplicação do ácido abscísico (S-ABA) na qualidade fenólica das cultivares Primitivo e Malbec (Vitis vinifera L.). O experimento foi conduzido em um vinhedo comercial em Santa Catarina, Brasil, com duas cultivares de videira Primitivo e Malbec (V. vinífera L.), respectivamente, por dois ciclos consecutivos: 2015/2016 e 2016/2017. O delineamento experimental foi em blocos casualizados, consistindo em seis tratamentos: 1) testemunha (sem tratamento); 2) desfolha manual no início da maturação (DIM); 3) desfolha manual quinze dias após a primeira desfolha (D15); 4) S-ABA 200 mg L-1 (ABA200); 5) S-ABA $400 \mathrm{mg} \mathrm{L}-1$ (ABA400); 6) S-ABA $600 \mathrm{mg} \mathrm{L-1}$ (ABA600), quatro repetições e três plantas por parcela. Com os dados obtidos, realizou-se o teste de normalidade por Kolmogorov-Smirnov ao nível de 5\% de significância, empregando a análise de variância (ANOVA) e, posteriormente, a Análise de Componentes Principais (ACP) com o objetivo de analisar a relação entre os parâmetros analisados, utilizando o software R. Após a discussão dos resultados, conclui-se que a aplicação exógena de S-ABA fornece níveis mais altos de flavonoides totais, luminosidade e cromaticidade em videiras cvs. Malbec e Primitivo e que a aplicação de S-ABA promoveu desfolha com $600 \mathrm{mg} \mathrm{L}-1$, podendo ser uma alternativa para reduzir custos de produção. A desfolha forneceu um aumento na intensidade de cor e no ângulo Hue em bagas cv. Malbec e Primitivo, em que tal fator pode estar relacionado à maior incidência de radiação nos cachos, causada pela remoção das folhas.
\end{abstract}

Palavras-chave: Vitis vinífera; Cor; Fitoreguladores; Manejo cultural.

\begin{abstract}
The color and stability of anthocyanins in fruits are largely influenced by temperature, light and $\mathrm{pH}$. In this sense, the present work aimed to evaluate the management of defoliation and the application of abscisic acid (S-ABA) in the phenolic quality of the cultivars Primitivo and Malbec (Vitis vinifera L.). The experiment was conducted in a commercial vineyard in Santa Catarina, Brazil, with two cultivars of vine Primitivo and Malbec ( $V$. vinifera L.), respectively, for two consecutive cycles: 2015/2016 and 2016/2017. The experimental design was in randomized blocks, consisting of six treatments: 1) control (without treatment); 2) manual defoliation at the beginning of maturation (DIM); 3) manual defoliation fifteen days after the first defoliation (D15); 4) S-ABA $200 \mathrm{mg}$ L-1 (ABA200); 5) S-ABA 400 mg L-1 (ABA400); 6) S-ABA 600 mg L-1 (ABA600), four replicates and three plants per
\end{abstract}


plot. With the data obtained, the Kolmogorov-Smirnov normality test was performed at the 5\% level of significance, using analysis of variance (ANOVA) and, subsequently, Principal Component Analysis (ACP) in order to analyze the relation between the analyzed parameters, using the software R. After the discussion of the results, it is concluded that the exogenous application of S-ABA provides higher levels of total flavonoids, luminosity and chromaticity in cvs grapevines. Malbec and Primitivo and that the application of S-ABA promoted defoliation with $600 \mathrm{mg} \mathrm{L}-1$, which can be an alternative to reduce production costs. Defoliation provided an increase in color intensity and Hue angle in cv. Malbec and Primitivo, in which this factor may be related to the higher incidence of radiation in the bunches, caused by the removal of the leaves.

Keywords: Vitis vinifera; Color; Phytoregulators; Cultural management.

\section{Resumen}

El color y la estabilidad de las antocianinas en los frutos están influenciados en gran medida por la temperatura, la luz y el pH. En este sentido, el presente trabajo tuvo como objetivo evaluar el manejo de la defoliación y la aplicación de ácido abscísico (S-ABA) en la calidad fenólica de los cultivares Primitivo y Malbec (Vitis vinifera L.). El experimento se realizó en un viñedo comercial en Santa Catarina, Brasil, con dos cultivares de vid Primitivo y Malbec (V. vinífera L.), respectivamente, durante dos ciclos consecutivos: 2015/2016 y 2016/2017. El diseño experimental fue en bloques al azar, compuesto por seis tratamientos: 1) control (sin tratamiento); 2) defoliación manual al inicio de la maduración (DIM); 3) defoliación manual quince días después de la primera defoliación (D15); 4) S-ABA 200 mg L-1 (ABA200); 5) S-ABA 400 mg L-1 (ABA400); 6) S-ABA 600 mg L-1 (ABA600), cuatro repeticiones y tres plantas por parcela. Con los datos obtenidos se realizó la prueba de normalidad de Kolmogorov-Smirnov al nivel de significancia del 5\%, mediante análisis de varianza (ANOVA) y, posteriormente, Análisis de Componentes Principales (ACP) para analizar la relación entre los parámetros analizados, utilizando el software R. Luego de la discusión de los resultados, se concluye que la aplicación exógena de S-ABA proporciona niveles más altos de flavonoides totales, luminosidad y cromaticidad en vides cvs. Malbec y Primitivo y que la aplicación de S-ABA promovió la defoliación con $600 \mathrm{mg}$ L1, lo que puede ser una alternativa para reducir costos de producción. La defoliación proporcionó un aumento en la intensidad del color y el ángulo de tono en el cv. Malbec y Primitivo, en los que este factor puede estar relacionado con la mayor incidencia de radiación en los racimos, provocada por la remoción de las hojas.

Palabras clave: Vitis vinifera; Color; Fitoreguladores; Gestión cultural.

\section{Introdução}

A videira (Vitis sp.) é uma das espécies frutíferas mais importantes em todo o mundo e é reconhecida por ser exigente nos tratos culturais e condições edafoclimáticas, os quais afetam a duração dos estádios fenológicos, maturação dos cachos, qualidade e produtividade da uva. Uma vez que não alcançadas estas exigências, principalmente em relação à pluviosidade e amplitude térmica, as uvas podem não alcançar os índices ideais de maturação (Biniari et al., 2020; Teslić et al., 2019). Em termos de qualidade para a maturação, um dos aspectos mais importantes é a coloração das bagas, fator determinante para seu valor comercial e funcional, sendo controlado pelo conteúdo e tipo de antocianinas (Ding et al., 2020, Vitulo et al., 2019).

As antocianinas, compostos fenólicos pertencentem ao grupo dos flavonoides, são amplamente distribuídas na natureza e responsáveis pela maioria da coloração azul, violeta e tonalidades de vermelho presentes em frutos. Desempenham várias funções, como atividade antioxidante e proteção da luz UV e acumulam-se principalmente nas células hipodérmicas de paredes espessas da epiderme (Abe et al., 2007; Petrussa et al., 2013). Acredita-se que este acúmulo seja regulado por uma complexa interação entre os fitormonios, principalmente ácido abscísico (ABA) e etileno (Coelho et al., 2019; Khun et al., 2013; Mori; Sugaya; Gemma, 2005).

A expressão das antocianinas depende de fatores internos, como o enântiomero $\mathrm{S}$ do ácido abscísico $(S$-ABA), que induz o fator de transcrição $M Y B 1 A$, proteína encarregada de regular a transcrição de genes que compõem a rota biossintética das antocianinas das uvas tintas (Jeong et al., 2004; Pastore et al., 2013). Vários trabalhos sugerem que aplicações exógenas de $S$-ABA antecipam a época de colheita, aumentando as concentrações de antocianinas e proantocianinas nas cascas das uvas, com considerável melhoria em sua coloração, proporcionando maior uniformidade e qualidade (Koyama et al., 2019; Pessenti et al., 2019; Pessenti et al., 2017).

Outro componente muito importante na síntese de antocianinas é o acúmulo de açúcares, pois além de influenciarem a quantidade de álcool na vinificação, também originam outros compostos, como as antocianinas. O acúmulo de sólidos solúveis 
está positivamente relacionado à exposição dos cachos a exposição solar, pois quanto maior a intensidade de radiação solar incidente, maior a concentração de açúcares (Abe et al., 2007; Teixiera, 2004). Uma prática de manejo da videira que auxilia nisto é a poda verde, a qual tem como intuito o equilíbrio entre o desenvolvimento vegetativo e produtivo, buscando favorecer a qualidade da uva (Almeida \& Ono, 2017).

Outra prática de manejo que auxilia na síntese de antocianinas é a poda verde, a qual tem como intuito o equilíbrio entre o desenvolvimento vegetativo e produtivo, buscando favorecer a qualidade da uva (Almeida \& Ono, 2017). Uma modalidade de poda verde, é a desfolha, a qual se define como a eliminação das folhas, favorecendo o arejamento e insolação nas inflorescências e cachos de uva, maximizando a maturação da uva (Almeida; Ono, 2017; Radunz et al., 2013), melhorando a composição química dos cachos e produtividade (Würz, Allebrandt, Filho, Bem, Brighenti, Outemane, et al., 2018; Würz, Allebrandt, Filho, Bem, Brighenti, Rufato, et al., 2018), maior teor de açúcar, antocianinas e compostos fenólicos, e menor acidez titulável, pH e concentração de ácido málico (Baiano et al., 2015).

O objetivo deste trabalho foi avaliar o manejo da desfolha e da aplicação do ácido abscísico ( $S$-ABA), na qualidade fenólica de uvas das cultivares Primitivo e Malbec.

\section{Metodologia}

$\mathrm{O}$ experimento foi conduzido em um vinhedo comercial com duas cultivares de videira Primitivo e Malbec ( $V$. vinífera L.), por dois ciclos consecutivos: 2015/2016 e 2016/2017. A área do vinhedo comercial está situada em Água Doce, Estado de Santa Catarina, Brasil, com coordenadas geográficas de 26²3'53"S e 51³0'42"O e 1249 metros de altitude. O vinhedo foi implantado em 2006 sob o porta enxerto 'Paulsen 1103', sendo conduzido em espaldeira no sistema Guyot, com espaçamento de 1,5 m entre plantas e 3,0 m entre linhas.

O clima característico do local de acordo com Köppen é o $\mathrm{Cfb}$ - clima temperado marítimo úmido com verão temperado (Alvares et al., 2013). O bioma Mata Atlântica com vegetação do tipo Estepe são as condições que predominam no local de estudo (IBGE, 2020). O local tem temperatura média de $16.7^{\circ} \mathrm{C}$ e pluviosidade média de $1860 \mathrm{~mm}$ (INMET, 2020).

O delineamento experimental foi em blocos casualizados, com 6 tratamentos, 4 repetições e 3 plantas por parcela, da qual foi utilizada como área útil para avaliar a planta central. Os tratamentos foram: 1) testemunha (sem tratamento); 2) desfolha manual no início da maturação (DIM); 3) desfolha manual quinze dias após a primeira desfolha (D15); 4) $S$-ABA 200 $\mathrm{mg} \mathrm{L}^{-1}$ (ABA200); 5) S-ABA $400 \mathrm{mg} \mathrm{L}^{-1}$ (ABA400); 6) S-ABA $600 \mathrm{mg} \mathrm{L}^{-1}$ (ABA600). As aplicações das soluções aquosas de $S$-ABA (Valent BioSciences Corporation, Libertyville, IL, EUA) foram realizadas no início da maturação dos cachos (fase de pintor) com o uso de um pulverizador costal até o ponto de escorrimento, sendo aplicado diretamente nas folhas até a altura dos cachos. A desfolha foi realizada no início da maturação e 15 dias após a data da primeira desfolha até altura dos cachos, sendo retiradas até 6 folhas por ramo.

Após a colheita, os cachos foram acondicionados em câmara fria até estabilizar a temperatura a $18^{\circ} \mathrm{C}$. Posteriormente, as bagas foram desengaçadas e armazenadas no freezer a $-4{ }^{\circ} \mathrm{C}$ para análises posteriores. As análises referentes à cor dos extratos feito com as bagas, foram efetuadas segundo o método de Iland (2013). O conteúdo de $1 \mathrm{~g}$ de casca separado antecipadamente foi retirado do ultrafreezer (armazenadas por um mês) e macerado em cadinhos de porcelana junto a $10 \mathrm{~mL}$ de solução extratora $(50 \%$ de etanol $95 \%+50 \%$ de ácido clorídrico $1,5 \mathrm{M})$. Com as amostras totalmente maceradas, o conteúdo líquido foi armazenado em tubo de ensaio protegido da luz (coberto por papel alumínio), realizando-se em seguida a lavagem do restante do macerado preso ao cadinho, adicionando-se mais $15 \mathrm{~mL}$. O extrato foi diluído na proporção 1:10 e analisado em espectrofotômetro modelo UV 1650 PC (Shimadzu, Kyoto, Japão) nos comprimentos de onda de 420, 520 e 620 nm. A intensidade de cor foi obtida através da formula Abs420 + Abs520 + Abs620. 
Para a quantificação do teor de flavonoides totais foi utilizado o método proposto por Lees e Francis (1972). Após os tubos de ensaio receberem toda a solução macerada e deixados sob refrigeração a $4{ }^{\circ} \mathrm{C}$ por 20 horas. Ao término deste período, o extrato foi filtrado, lavando-o com $25 \mathrm{~mL}$ da solução extratora, deixando o total do extrato em frasco coberto com papel alumínio por duas horas. Em seguida, foram retirados $2 \mathrm{~mL}$ do extrato, adicionando-se $10 \mathrm{~mL}$ da solução extratora e posterior agitação em vortex. A leitura da amostra foi feita em espectrofotômetro modelo UV 1650 PC (Shimadzu, Kyoto, Japão) a 374 $\mathrm{nm}$ para a determinação do teor de antocianinas, sendo os valores expresso em $\mathrm{mg}$ de antocianinas por $100 \mathrm{~g}$ de material vegetal, para ambas as determinações, respectivamente. Para quantificação do teor de flavonoides a equação (VA*FD) *76,6 ${ }^{-1}$, em que VA = valor da absorbância e FD = fator de diluição.

A coloração das bagas foi determinada com auxílio de um colorímetro, modelo Croma meter CR-400/410 (Minolta, Osaka, Japão). Os valores foram expressos na coordenada-padrão CIE $L^{*} a^{*} b^{*}$, em que $L^{*}$ representa o brilho de uma superfície $\left(L^{*}=100=\right.$ branco; $L^{*}=0=$ preto); $a^{*}$ representa a intensidade de cor do verde ao vermelho $\left(a^{*}\right.$ mais negativo= mais verde; $a^{*}$ mais positivo $=$ mais vermelho), e $b^{*}$ mede a intensidade de cor do amarelo ao azul $\left(b^{*}=\right.$ mais positivo $=$ mais amarelo; $b^{*}=$ mais negativo $=$ mais azul). Os valores de $a^{*}$ e $b^{*}$ foram utilizados para calcular a tonalidade de cor $\mathrm{C}^{*}$, pela fórmula $C^{*}=\left(a^{*} 2+b^{* 2}\right)^{1 / 2}$ e o ângulo $H^{*}($ Carreño et al., 1995).

$\mathrm{Na}$ análise dos dados, foi realizada o teste de normalidade dos dados por Kolmogorov-Smirnov ao nível de 5\% de significância. Empregou-se a análise de variância (ANOVA), posteriormente o coeficiente de correlação de Pearson (r) nas variáveis significativas. Em seguida a Análise de Componentes Principais (ACP) foi realizada usando as variáveis com o objetivo analisar a relação entre os parâmetros analisados. O software utilizado foi o R (R Core Team, 2020), utilizando o pacote ExpDes e FactoMineR.

\section{Resultados e Discussão}

Na Figura 1, observa-se a análise de correlação de Pearson para a cv. Malbec na safra 2015/16, com as variáveis de qualidade fenólica. Há correlação positiva entre a cromaticidade e o luminosidade (L). Contudo, houve correlação negativa entre intensidade e tratamento. O sinal do coeficiente de correlação linear de Pearson expressa o sentido da correlação, e sua intensidade é representada por um valor numérico que oscila entre -1 e 1. Em situações extremas, dois caracteres podem apresentar correlação linear negativa perfeita $(r=-1)$ ou positiva perfeita $(r=1)$ ou, ainda, ausência de relação linear $(r=0)$. 
Figura 1 - Correlação de Pearson de atributos fenólicos e de cor para a cv. Malbec na safra 2015/16. TEST: testemunha (controle); ABA200: aplicação de S-ABA 200 mg L-1; ABA400: aplicação de S-ABA 400 mg L-1; ABA600: aplicação de SABA 600 mg L-1; DIM: desfolha manual no início da maturação; D15: desfolha manual quinze dias após a primeira desfolha.

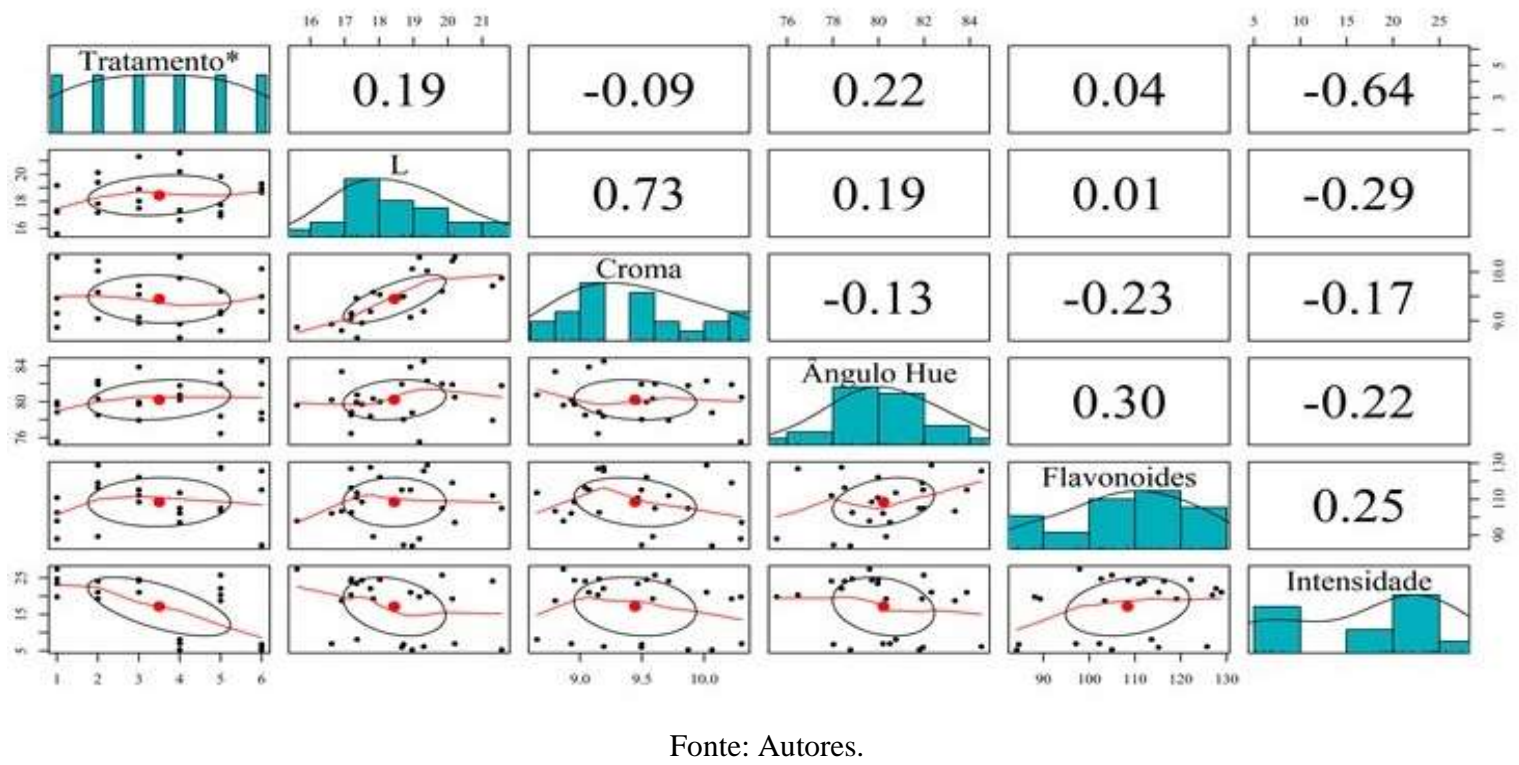

A análise de componentes principais (ACP) na cv. Malbec durante safra 2015/2016 explicou 82,3\% da variância total dos dados nos dois primeiros componentes (Figura 2). O primeiro componente separa em escore positivo as características de cor e em escores negativos as fenólicas. Enquanto que o segundo separa o atributo cromaticidade em escore negativo e as demais em escore positivo. Sugiro colocar as figuras em seguidas logo após ter chamado.

Há maior correlação do tratamento ABA600 com os flavonoides totais, e ABA400 com as variáveis ângulo hue e L. A intensidade se correlacionou com a desfolha manual no início da maturação (DIM). E a cromaticidade foi correlacionada com a testemunha e desfolha manual quinze dias após a primeira (D15).

Figura 2 - Análises de Componentes Principais de atributos fenólicos e de cor para a cv. Malbec na safra 2015/16. TEST: testemunha (controle); ABA200: aplicação de S-ABA 200 mg L-1; ABA400: aplicação de S-ABA 400 mg L-1; ABA600: aplicação de S-ABA 600 mg L-1; DIM: desfolha manual no início da maturação; D15: desfolha manual quinze dias após a primeira desfolha.

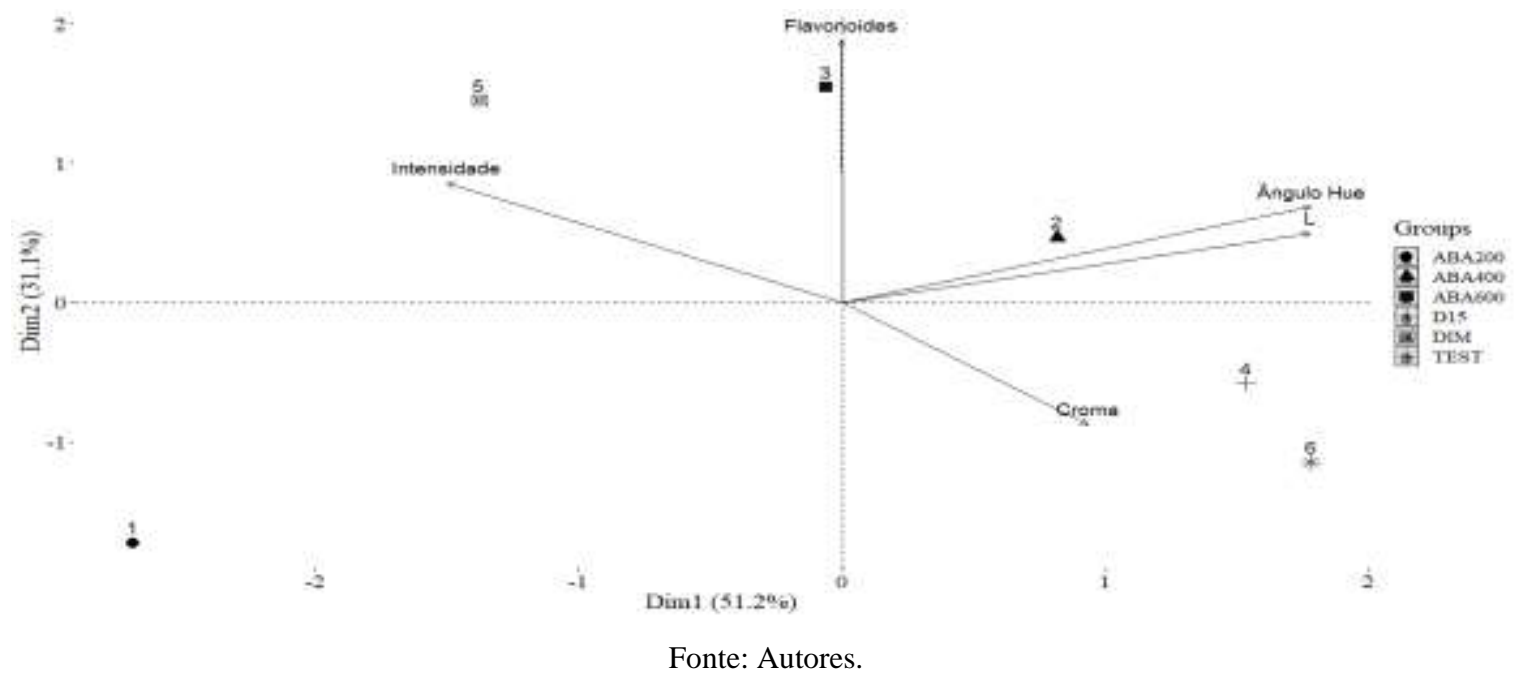


A correlação na safra 2016/17 para a cv. Malbec foi positiva entre as variáveis cromaticidade e L. E maior correlação negativa entre ângulo hue e cromaticidade (Figura 3).

Figura 3 - Correlação de Pearson de atributos de cor para a cv. Malbec na safra 2016/17. TEST: testemunha (controle); ABA200: aplicação de S-ABA 200 mg L-1; ABA400: aplicação de S-ABA 400 mg L-1; ABA600: aplicação de S-ABA 600 mg L-1; DIM: desfolha manual no início da maturação; D15: desfolha manual quinze dias após a primeira desfolha.

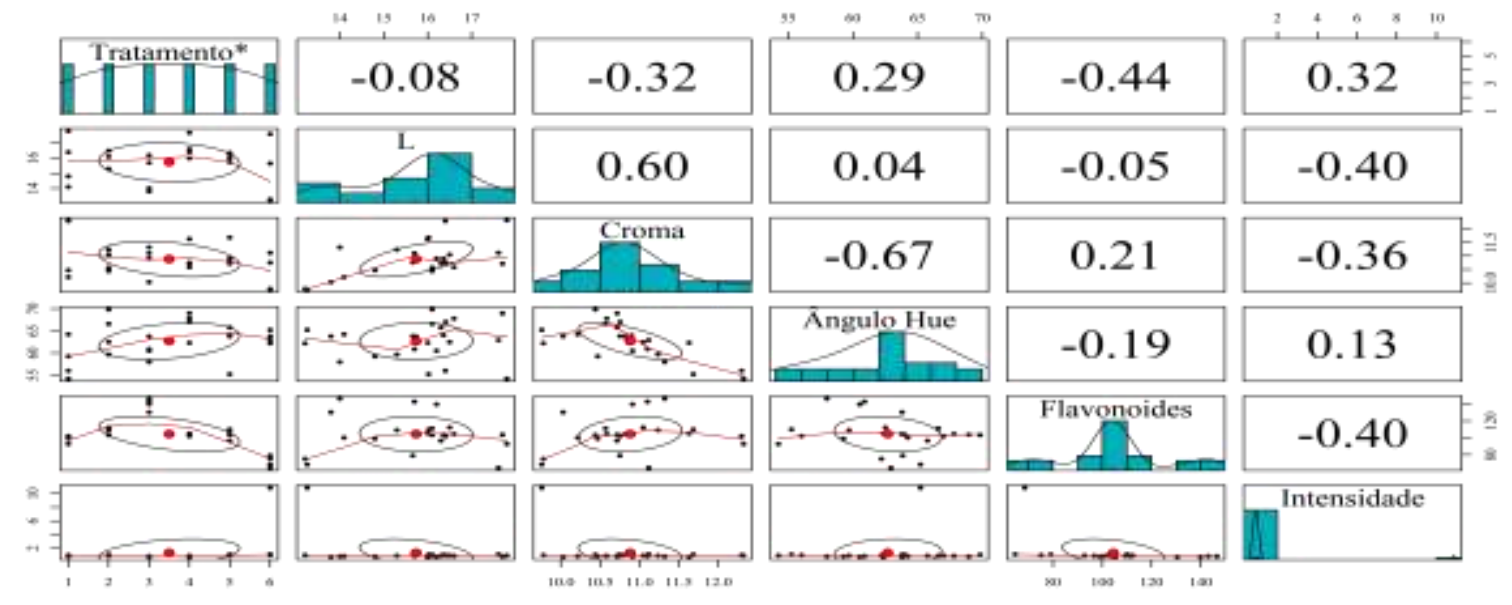

Fonte: Autores.

Na Figura 4, na Análise de Componentes Principais (ACP) para a cv. Malbec na safra 2016/2017, as dimensões 1 e 2 representam 82,9 \% da variação total. A dimensão 1 separa em escore positivo as características cromaticidade, flavonoides e L, e em escores negativos intensidade e ângulo hue. A dimensão 2 separa os atributos fenólicos em escore negativo e as demais em escore positivo.

A intensidade não foi correlacionada pelos tratamentos, exceto pela testemunha. Observa-se que é inversamente proporcional à variável L, sendo está correlacionada com ABA400 e D15. A cromaticidade foi influenciada pelo DIM. Flavonoides pelo tratamento ABA200.

Figura 4 - Análises de Componentes Principais de atributos de cor para a cv. Malbec na safra 2016/17. TEST: testemunha (controle); ABA200: aplicação de S-ABA 200 mg L-1; ABA400: aplicação de S-ABA 400 mg L-1; ABA600: aplicação de SABA 600 mg L-1; DIM: desfolha manual no início da maturação; D15: desfolha manual quinze dias após a primeira desfolha.

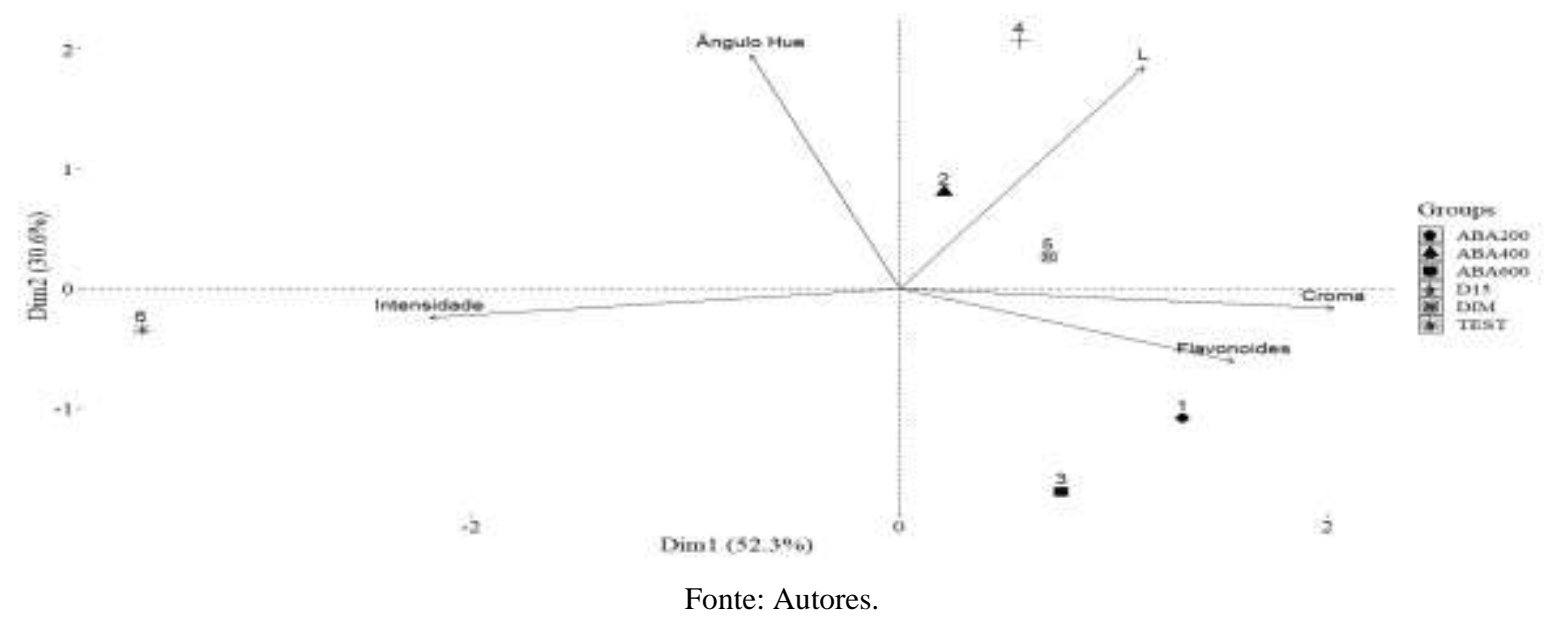


A correlação para a cv. Primitivo na safra 2015/16 foi similar com a Malbec, correlações positivas entre croma e L, ângulo hue e tratamento e, entre intensidade e tratamento. Assim como a correlação negativa entre ângulo hue e croma, flavonoides e tratamento (Figura 5).

Figura 5 - Correlação de Pearson de atributos de cor para a cv. Primitivo na safra 2015/16. TEST: testemunha (controle); ABA200: aplicação de S-ABA 200 mg L-1; ABA400: aplicação de S-ABA 400 mg L-1; ABA600: aplicação de S-ABA 600 mg L-1; DIM: desfolha manual no início da maturação; D15: desfolha manual quinze dias após a primeira desfolha.

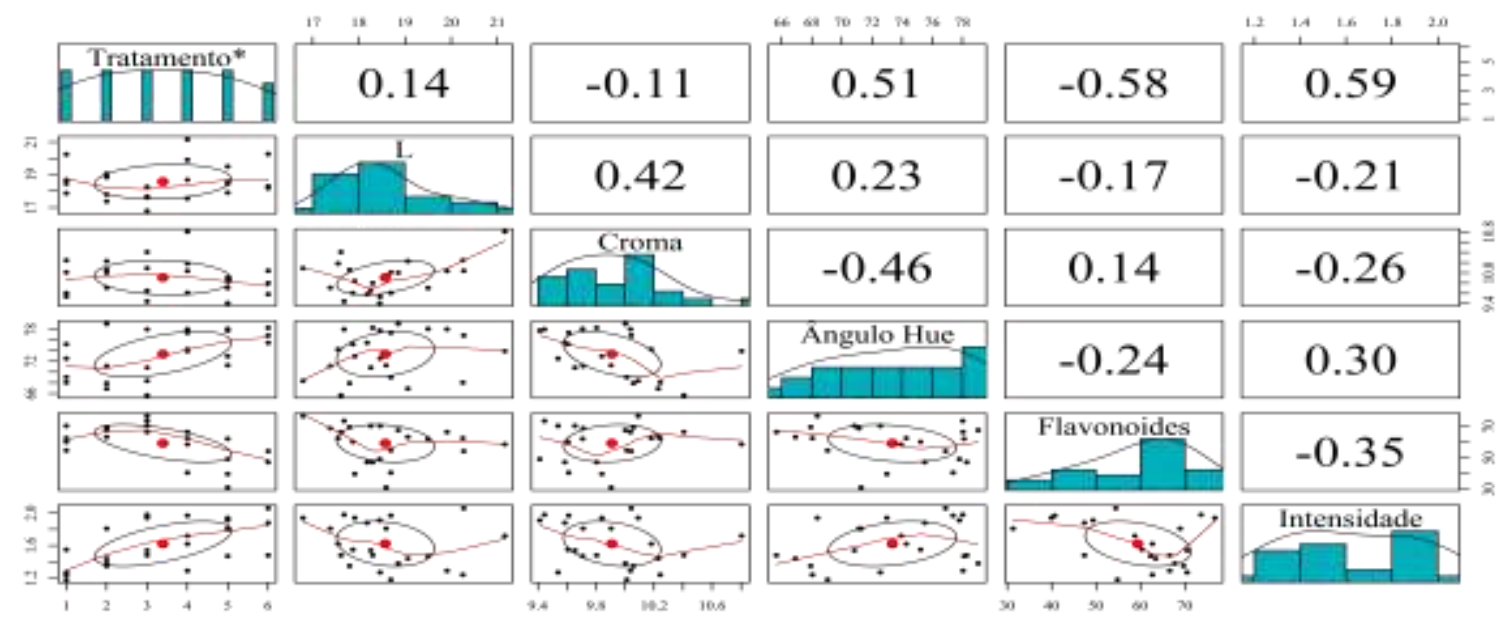

Fonte: Autores.

Na Análise de Componentes Principais (ACP) para a cv. Primitivo na safra 2015/2016 (Figura 6), as dimensões 1 e 2 representam 82,9 \% da variação total. A dimensão 1 separa em escore positivo as características intensidade, ângulo hue e L, e em escores negativos croma e flavonoides. A dimensão 2 separa o atributo intensidade em escore negativo e as demais em escore positivo.

O croma não foi correlacionada pelos tratamentos, sendo esta inversamente proporcional à variável intensidade de cor, que está correlacionada com o tratamento DIM. Os flavonoides totais se correlacionam com as doses de 200 e $400 \mathrm{mg}$ L-1 de S-ABA e o L com o tratamento D15. 
Figura 6 - Análises de Componentes Principais de atributos de cor para a cv. Primitivo na safra 2015/16. TEST: testemunha (controle); ABA200: aplicação de S-ABA 200 mg L-1; ABA400: aplicação de S-ABA 400 mg L-1; ABA600: aplicação de SABA 600 mg L-1; DIM: desfolha manual no início da maturação; D15: desfolha manual quinze dias após a primeira desfolha.

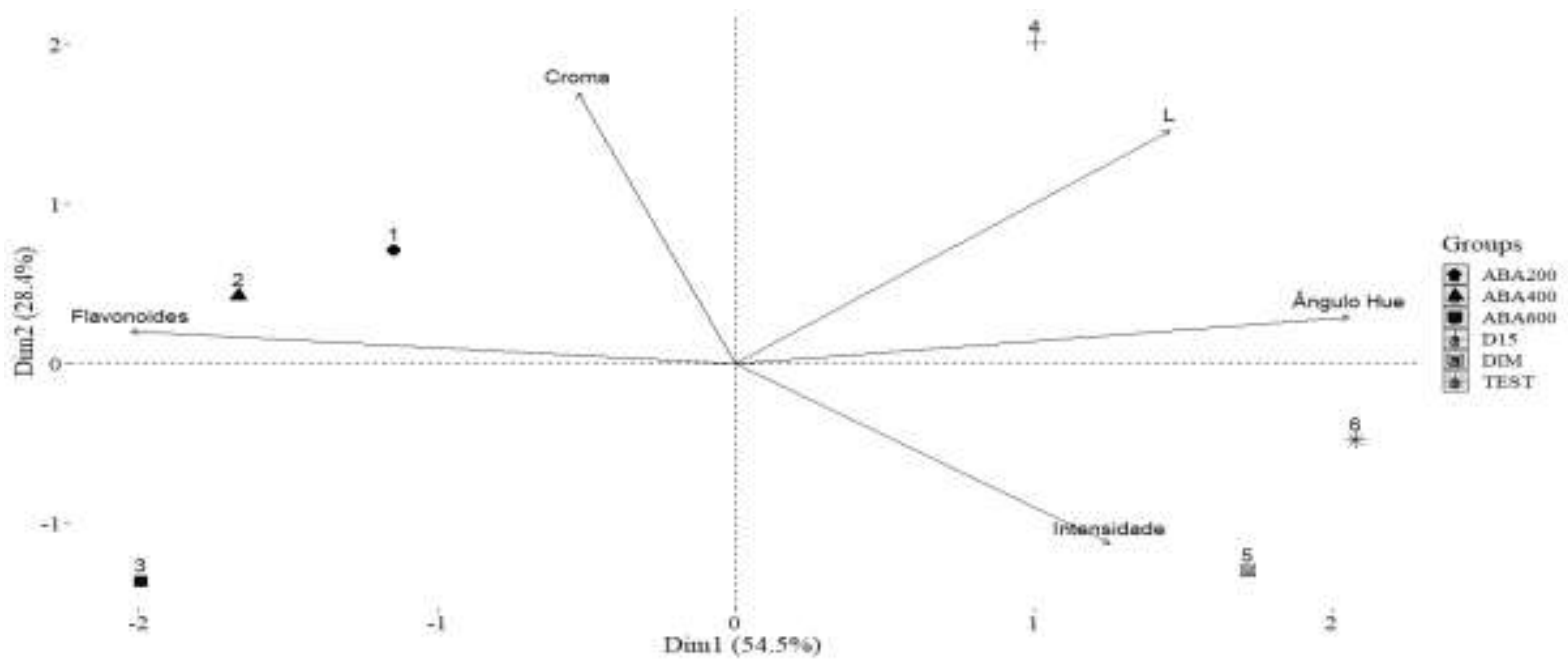

Fonte: Autores.

Para as correlações positivas na safra 2016/17 com a cv. Primitivo, o mesmo ocorreu que a safra anterior, entre croma e L. A correlação entre ângulo hue com o croma foi negativa, assim como tratamento e intensidade (Figura 7).

Figura 7 - Correlação de Pearson de atributos de cor para a cv. Primitivo na safra 2016/17. TEST: testemunha (controle); ABA200: aplicação de S-ABA 200 mg L-1; ABA400: aplicação de S-ABA 400 mg L-1; ABA600: aplicação de S-ABA 600 mg L-1; DIM: desfolha manual no início da maturação; D15: desfolha manual quinze dias após a primeira desfolha.

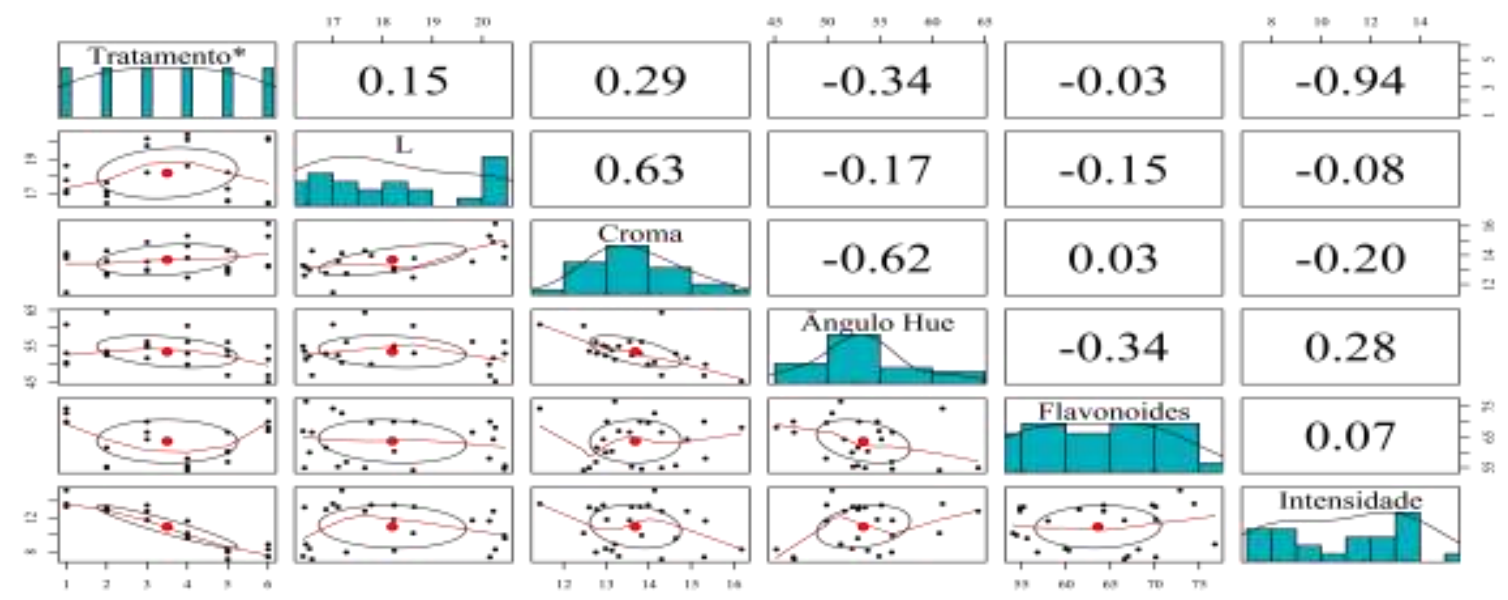

Fonte: Autores.

Na Figura 8, a Análise de Componentes Principais (ACP) para a cv. Primitivo na safra 2016/2017, mostra que as dimensões 1 e 2 representam 76,7 \% da variação total. A dimensão 1 separa em escore positivo as características intensidade, ângulo Hue, e em escores negativos croma, flavonoides totais e intensidade. A dimensão 2 separa o atributo flavonoides totais em escore negativo e as demais em escore positivo.

A cromaticidade não foi correlacionada pelos tratamentos, sendo esta inversamente proporcional à variável intensidade de cor, que está correlacionada com o tratamento ABA400. Os flavonoides totais se correlacionam com a desfolha 
manual no início da maturação, o L, ângulo hue e intensidade foram correlacionados com D15, ABA600 e ABA400, respectivamente.

Figura 8 - Análises de Componentes Principais de atributos de cor para a cv. Primitivo na safra 2016/17. TEST: testemunha (controle); ABA200: aplicação de S-ABA 200 mg L-1; ABA400: aplicação de S-ABA 400 mg L-1; ABA600: aplicação de SABA 600 mg L-1; DIM: desfolha manual no início da maturação; D15: desfolha manual quinze dias após a primeira desfolha.

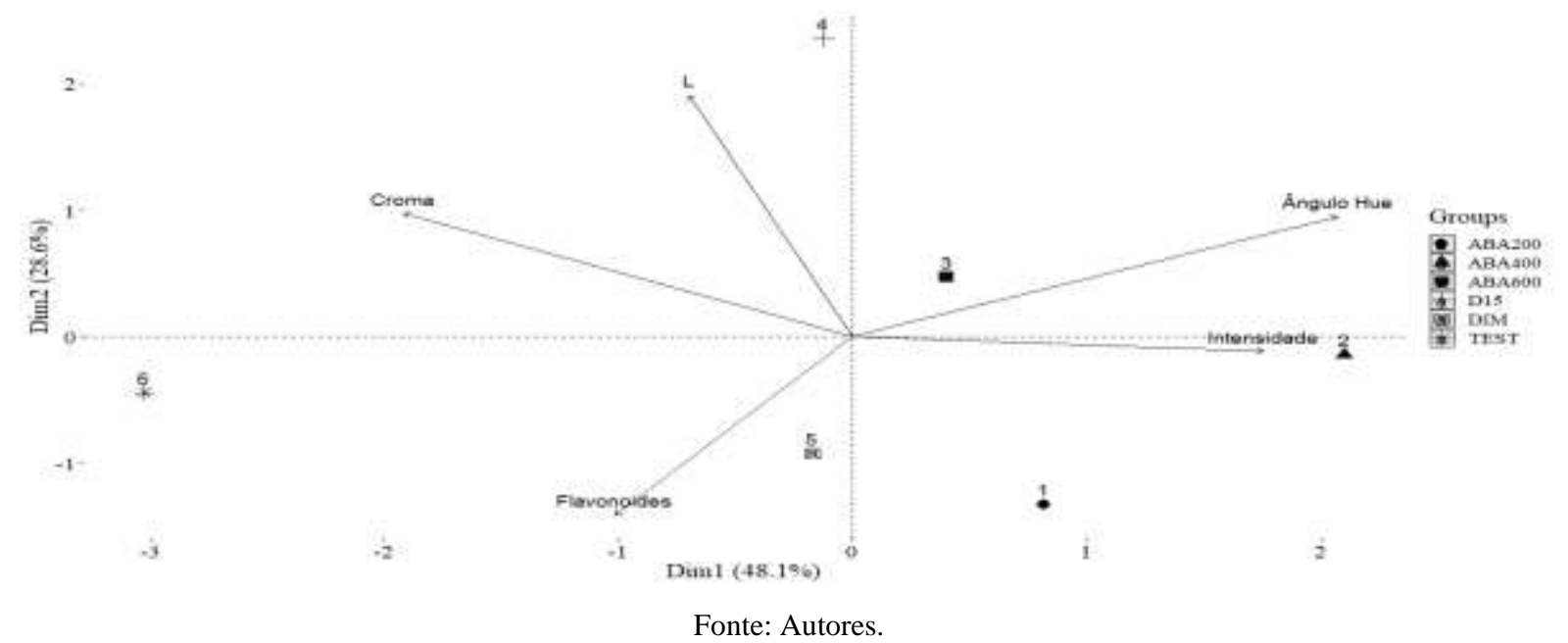

Para a cv. Malbec, nas duas safras, observa-se que os flavonoides totais foram influenciados pelas doses de ácido abscísico (Figuras 2 e 4). Sabe-se que o início da biossíntese dos flavonoides, como a expressão das antocianinas depende de fatores internos, como o ácido abscísico (S-ABA), que induz o fator de transcrição MYB1A, proteína encarregada de regular a transcrição de genes que compõem a rota biosintética dos flavonoides das uvas tintas (Jeong et al., 2004). Segundo Kataoka et al. (1982), o ABA também tem sido associado ao processo fisiológico de maturação de uvas, incluindo o acúmulo de flavonoides nas cascas das bagas.

Segundo González-Nevez et al. (2011), os principais compostos fenólicos encontrados nas uvas e nos vinhos são classificados em: flavonóides e não-flavonóides. Os compostos flavonoides representam o maior grupo de polifenóis encontrados nos alimentos (Scalbert \& Williamson, 2000), apresentando alto teor de antioxidantes. Caracterizam-se por um esqueleto básico e comum de C6-C3-C6. Os flavonoides mais comuns presentes nas uvas e nos vinhos tintos abrangem os flavanóis, os flavonóis e as antocianinas. Esses compostos são responsáveis pelas características de cor e estrutura dos vinhos (Downey et al., 2006; Spáčil et al., 2008).

Os resultados corroboram com os obtidos por Koyama et al. (2014), que independente das concentrações e frequência de aplicação, obtiveram incremento na biossíntese do flavonoides no suco de uva 'Isabel', assim como os verificados por Jeong et al. (2004), em que a aplicação de S-ABA estimulou o acúmulo na uva 'Cabernet Sauvignon'. Gardin et al. (2012) observaram incremento no teor de flavonoides (antocianinas) com a aplicação de ABA e etefon. Ambos os reguladores vegetais atuam na biossíntese desses compostos, principalmente o S-ABA que atua direto na síntese de antocianinas. Este mesmo autor afirma que os níveis de pigmentação nas cascas das uvas tratadas com $S$-ABA foram acompanhados por maior atividade da CHFI (chalcona-flavona isomerase). A atividade da CFHI está estreitamente relacionada com a biossíntese de flavonoides totais.

Para os atributos de cor $\mathrm{L}^{*}$ e ângulo hue foram encontradas correlação com $S$-ABA em um ciclo para a cultivar Malbec (Figuras 3 e 5), assim como para a cv. Primitivo, o ângulo hue também foi influenciado (Figuras 9). Esses dados são confirmados pela correlação de Pearson para as duas cultivares, em que o a cromaticidade possui correlação linear negativa 
com o ângulo hue, demonstrando que quanto maior o ângulo hue (Figuras 4 e 6), menor o valor de cromaticidade (maior saturação nas bagas). Isto também pode ser verificado pela correlação linear positiva entre croma e o L, quanto maior a luminosidade de uma baga, maior será a sua cromaticidade (Figuras 2, 4, 6 e 8). Roberto et al. (2013), em uvas 'Rubi', observaram os menores valores para o $\mathrm{L}^{*}$ e $\mathrm{C} *$ quando aplicado $\mathrm{S}-\mathrm{ABA}$, indicando que as bagas obtiveram cor mais escura (L*) e menor valor de saturação $\left(C^{*}\right)$. Koyama et al. $(2014,2018,2019)$ e Yamamoto et al. (2019) também encontraram resultados similares para estes índices em uvas tintas.

A desfolha manual se correlacionou com o atributo de cor cromaticidade, resultando em menores valores de saturação para a cv. Malbec. Para a Primitivo nas duas safras, o L foi influenciado pela desfolha 15 dias após o início da maturação, demonstrando que esse procedimento deixa as bagas mais escuras. Esses dados são confirmados pela análise de correlação linear positiva entre o L e cromaticidade (Figuras 2, 4, 6 e 8), que mostrou que quanto maior a luminosidade nas bagas, maior a saturação de cor das mesmas. Cores puras possuem alta saturação e, portanto, mais brilhantes na percepção humana.

A variável intensidade de cor foi influenciada pela desfolha em pelo menos um dos ciclos nas cvs. Malbec e Primitivo (Figuras 3 e 7). Würz et al. (2018) afirmam que as desfolhas realizadas nos estádios fenológicos plena florada, grão chumbinho, grão ervilha e virada de cor resultaram em incremento da coloração das bagas da videira Cabernet Sauvignon em relação à desfolha realizada 15 dias após a virada de cor e as plantas não submetidas ao manejo da desfolha, que apresentam os valores inferiores de cor da extração das cascas.

A radiação solar incidente sobre a baga aumenta a sua temperatura e durante o dia pode resultar em aumento de $11{ }^{\circ} \mathrm{C}$ ou mais comparado com bagas naturalmente sombreadas pelas folhas, de acordo com a hora do dia e as condições climáticas (Bledsoe et al., 1988). Tem sido sugerido que a temperatura da casca das bagas tem mais influência no aumento da coloração do que a luz (Mori et al., 2005; Spayd et al., 2002), com isso, a desfolha pode propiciar aumento da temperatura na casca das bagas Malbec, promovendo aumento da coloração.

Tanto a intensidade de cor quanto a tonalidade são atributos importantes para uvas viníferas, pois através de seu aspecto são obtidas informações sobre suas qualidades e possíveis defeitos. Isto é consistente, pois o aumento do teor de flavonoides aumenta também a intensidade de cor dos vinhos. Além disso, a relação entre flavonoides e compostos fenólicos sobre a qualidade do vinho é de extrema importância, especialmente em vinhos com potencial de envelhecimento e amadurecimento (Würz, Allebrandt, Filho, Bem, Brighenti, Outemane, et al., 2018). Pessenti et al (2019) verificaram que a aplicação de $S$-ABA proporcionou desfolha de até $60 \%$ na altura dos cachos com dose de $600 \mathrm{mg} \mathrm{L}^{-1}$, isso contribui para o aumento de antocianinas e polifenóis totais na cv. Malbec.

Portanto, os resultados observados neste trabalho demonstram que o manejo da desfolha da videira influência os aspetos relacionados à cor da epiderme das uvas das cvs. Malbec e Primitivo, cultivada em regiões de elevada altitude de Santa Catarina, apresentando os benefícios esperados pelo vitivinicultor, com aumento do conteúdo de flavonoides e aumento da coloração da epiderme. A desfolha da videira deve ser considerada uma prática de manejo indispensável, visto que tem influência na qualidade fenólica das bagas.

\section{Conclusão}

A aplicação exógena de S-ABA fornece níveis mais altos de flavonoides totais, luminosidade e cromaticidade de uvas das cvs. Malbec e Primitivo. Em geral, a aplicação do S-ABA é uma ferramenta promissora para a viticultura, pois agrega valor ao produto final.

A desfolha fornece um aumento na intensidade de cor e no ângulo hue em bagas cv. Malbec e Primitivo, esse fator pode estar relacionado à maior incidência de radiação nos cachos, causada pela remoção das folhas. 


\section{Referências}

Abe, L. T., Mota, R. V. da, Lajolo, F. M., \& Genovese, M. I. (2007). Phenolic compounds and antioxidant activity of Vitis labrusca and Vitis vinifera cultivars. Food Science and Technology, 27(2), 394-400.

Almeida, M. B., \& Ono, E. O. (2017). Efeitos de diferentes níveis de desfolha sobre a fisiologia, a produção e a qualidade das uvas e dos vinhos da variedade Syrah em condições tropicais semiáridas brasileiras. Revista Semiárido De Visu, 4(3), 160-175. https://doi.org/(in Portuguese)

Alvares, C. A., Stape, J. L., Sentelhas, P. C., de Moraes Gonçalves, J. L., \& Sparovek, G. (2013). Köppen’s climate classification map for Brazil. Meteorologische Zeitschrift, 22(6), 711-728. https://doi.org/10.1127/0941-2948/2013/0507

Baiano, A., De Gianni, A., Previtali, M. A., Del Nobile, M. A., Novello, V., \& de Palma, L. (2015). Effects of defoliation on quality attributes of Nero di Troia (Vitis vinifera L.) grape and wine. Food Research International, 75, 260-269. https://doi.org/10.1016/j.foodres.2015.06.007.

Biniari, K., Xenaki, M., Daskalakis, I., Rusjan, D., Bouza, D., \& Stavrakaki, M. (2020). Polyphenolic compounds and antioxidants of skin and berry grapes of Greek Vitis vinifera cultivars in relation to climate conditions. Food Chemistry, 307, 125518. https://doi.org/10.1016/j.foodchem.2019.125518

Bledsoe, A. M., Kliewer, W. M., \& Marois, J. J. (1988). Effects of timing and severity of leaf removal on yield and fruit composition of Sauvignon blanc grapevines. American Journal of Enology and Viticulture, 39(1), 49-54.

Carreño, J., Martinez, A., Almela, L., \& Fernández-López, J. A. (1995). Proposal of an index for the objective evaluation of the colour of red table grapes. Food Research International, 28(4), 373-377.

Downey, M. O., Dokoozlian, N. K., \& Krstic, M. P. (2006). Cultural practice and environmental impacts on the flavonoid composition of grapes and wine: A review of recent research. American Journal of Enology and Viticulture, 57(3), 257-268.

Fiorillo, E., Crisci, A., De Filippis, T., Di Gennaro, S. F., Di Blasi, S., Matese, A., Primicerio, J., Vaccari, F. P., \& Genesio, L. (2012). Airborne high-resolution images for grape classification: Changes in correlation between technological and late maturity in a Sangiovese vineyard in Central Italy. Australian Journal of Grape and Wine Research, 18(1), 80-90.

Gardin, J. P. P., Schumacher, R. L., Bettoni, J. C., Petri, J. L., \& Souza, E. L. de. (2012). Abscisic acid and Etefom: Influence on the maturity and quality of Cabernet Sauvignon grapes. Revista Brasileira de Fruticultura, 34(2), 321-327.

González-Neves, G., Gil, G., Guzmán, F., \& Ferrer, M. (2011). Potencial polifenólico de la uva: Índices propuestos y posibles aplicaciones. Comunicata Scientiae, 2(2), 57-69.

IBGE. (2020). Instituto Brasileiro de Geografia e Estatísfica. http://www.ibge.gov.br/home/

Iland, P. (2013). Chemical analysis of grapes and wine: Techniques and concepts. Patrick Iland Wine Promotions.

INMET. (2020). Instituto Nacional de Meteorologia [Dados meteorológicos.]. Instituto Nacional de Meteorologia. http://www.inmet.gov.br

Jeong, S. T., Goto-Yamamoto, N., Kobayashi, S., \& Esaka, M. (2004). Effects of plant hormones and shading on the accumulation of anthocyanins and the expression of anthocyanin biosynthetic genes in grape berry skins. Plant Science, 167(2), 247-252.

Koyama, R., Colombo, R. C., Silva Borges, W. F., Silvestre, J. P., Hussain, I., Shahab, M., Ahmed, S., Prudencio, S. H., Teodoro de Souza, R., \& Roberto, S. R. (2019). Abscisic Acid Application Affects Color and Acceptance of the New Hybrid 'BRS Melodia' Seedless Grape Grown in a Subtropical Region. HortScience, 54(6), 1055-1060. https://doi.org/10.21273/HORTSCI13872-19

Koyama, R., de Assis, A. M., Yamamoto, L. Y., Borges, W. F., de Sá Borges, R., Prudêncio, S. H., \& Roberto, S. R. (2014). Exogenous abscisic acid increases the anthocyanin concentration of berry and juice from 'Isabel'grapes (Vitis labrusca L.). HortScience, 49(4), $460-464$.

Koyama, R., Roberto, S. R., de Souza, R. T., Borges, W. F. S., Anderson, M., Waterhouse, A. L., Cantu, D., Fidelibus, M. W., \& Blanco-Ulate, B. (2018). Exogenous Abscisic Acid Promotes Anthocyanin Biosynthesis and Increased Expression of Flavonoid Synthesis Genes in Vitis vinifera $\times$ Vitis labrusca Table Grapes in a Subtropical Region. Frontiers in Plant Science, 9. https://doi.org/10.3389/fpls.2018.00323

Lees, D. H., \& Francis, F. J. (1972). Standardization of pigment analyses in cranberries. HortScience.

MARIANI, L. (2012). Cambiamento climático e coltura della vite (Vol. 26). Rivista il Consenso.

Mori, K., Sugaya, S., \& Gemma, H. (2005). Decreased anthocyanin biosynthesis in grape berries grown under elevated night temperature condition. Scientia Horticulturae, 105(3), 319-330.

Pastore, C., Zenoni, S., Fasoli, M., Pezzotti, M., Tornielli, G. B., \& Filippetti, I. (2013). Selective defoliation affects plant growth, fruit transcriptional ripening program and flavonoid metabolism in grapevine. BMC Plant Biology, 13(1). https://doi.org/10.1186/1471-2229-13-30

Pessenti, I. L., Ayub, R. A., \& Botelho, R. V. (2019). Defoliation, application of S-ABA and vegetal extracts on the quality of grape and wine Malbec cultivar. Revista Brasileira de Fruticultura, 41(3). https://doi.org/10.1590/0100-29452019018

Pessenti, I. L., Ayub, R. A., \& Botelho, R. V. (2017). Quality of phenolic compounds of cv. Primitivo as a function of the defoliation and the application of abscisic acid. 20th GiESCO International Meeting, 1.

R Core Team. (2020). R: A Language and Environment for Statistical Computing. R Foundation for Statistical Computing. https://www.R-project.org/

Roberto, S. R., Assis, A. M. de, Yamamoto, L. Y., Miotto, L. C. V., Koyama, R., Sato, A. J., \& Borges, R. de S. (2013). Ethephon use and application timing of abscisic acid for improving color of'Rubi’table grape. Pesquisa Agropecuária Brasileira, 48(7), 797-800. 
Research, Society and Development, v. 10, n. 4, e39310414227, 2021

(CC BY 4.0) | ISSN 2525-3409 | DOI: http://dx.doi.org/10.33448/rsd-v10i4.14227

Scalbert, A., \& Williamson, G. (2000). Dietary intake and bioavailability of polyphenols. The Journal of nutrition, 130(8), 2073S-2085S.

Spáčil, Z., Nováková, L., \& Solich, P. (2008). Analysis of phenolic compounds by high performance liquid chromatography and ultra performance liquid chromatography. Talanta, 76(1), 189-199.

Spayd, S. E., Tarara, J. M., Mee, D. L., \& Ferguson, J. C. (2002). Separation of sunlight and temperature effects on the composition of Vitis vinifera cv. Merlot berries. American Journal of Enology and Viticulture, 53(3), 171-182.

Teslić, N., Vujadinović, M., Ruml, M., Ricci, A., Vuković, A., Parpinello, G. P., \& Versari, A. (2019). Future climatic suitability of the Emilia-Romagna (Italy) region for grape production. Regional Environmental Change, 19(2), 599-614. https://doi.org/10.1007/s10113-018-1431-6

Vitulo, N., Lemos, W. J. F., Calgaro, M., Confalone, M., Felis, G. E., Zapparoli, G., \& Nardi, T. (2019). Bark and Grape Microbiome of Vitis vinifera: Influence of Geographic Patterns and Agronomic Management on Bacterial Diversity. Frontiers in Microbiology, 9, 3203. https://doi.org/10.3389/fmicb.2018.03203

Würz, D. A., Allebrandt, R., Filho, J. L. M., Bem, B. P. de, Brighenti, A. F., Outemane, M., Rufato, L., \& Kretzschmar, A. A. (2018). Influência da época de desfolha no desempenho enológico da uva 'Cabernet Sauvignon' cultivada em região de altitude. Acta Iguazu, 7(2), 61-73.

Würz, D. A., Allebrandt, R., Filho, J. L. M., Bem, B. P. de, Brighenti, A. F., Rufato, L., \& Kretzschmar, A. A. (2018). Época de desfolha e sua influência no desempenho vitícola da uva 'Sauvignon Blanc' em região de elevada altitude. Revista de Ciências Agroveterinárias, 17(1), 91-99. https://doi.org/10.5965/223811711712018091

Yamamoto, L. Y., Koyama, R., Assis, A. M. de, Borges, W. F. S., Oliveira, I. R. de, \& Roberto, S. R. (2015). Color of berry and juice of "Isabel" grape treated with abscisic acid in different ripening stages. Pesquisa Agropecuária Brasileira, 50(12), 1160-1167. https://doi.org/10.1590/S0100-204X2015001200005. 